\title{
ORIGINAL ARTICLE \\ Pain, spasticity and quality of life in individuals with traumatic spinal cord injury in Denmark
}

\author{
SR Andresen ${ }^{1}$, F Biering-Sørensen ${ }^{2}$, EM Hagen ${ }^{1,3,4}$, JF Nielsen ${ }^{5}$, FW Bach ${ }^{6}$ and NB Finnerup ${ }^{7}$
}

Study design: Cross-sectional survey.

Objectives: To estimate the prevalence, predictors and impact of self-reported pain and spasticity and examine variables affecting quality of life in individuals with a traumatic spinal cord injury (SCI).

Setting: Nationwide, Denmark.

Methods: An anonymous questionnaire was sent out to individuals with a traumatic SCl. The questionnaire included questions about demographics and $\mathrm{SCl}$ characteristics, pain, spasticity and quality of life.

Results: In total, 537 questionnaires were completed. Seventy-three percent reported chronic pain of which $60 \%$ used descriptors suggestive of neuropathic pain. The average pain intensity and interference were 5.6 (s.d. 2.3) and 5.0 (s.d. 2.8), respectively, on a 0-10 numeric rating scale (NRS), and $28.1 \%$ reported severe pain. Seventy-one percent reported spasticity. Average interference of spasticity was 2.9 (s.d. 2.7). Quality of life scores were 6.5 (s.d. 2.5) for life and life situation, 5.5 (s.d. 2.6) for physical health and 6.7 (s.d. 2.6) for mental health on the NRS (0-10). Female gender was associated with lower mental health scores and tetraplegia with lower physical health scores, and high pain interference and shorter time since injury were associated with lower quality-of-life scores for all three parameters. Pain with descriptors suggestive of neuropathic pain was associated with lower quality-of-life scores than pain without such descriptors.

Conclusion: Chronic pain and spasticity are common problems after $\mathrm{SCl}$, and in particular, high pain interference is associated with lower quality of life.

Spinal Cord (2016) 54, 973-979; doi:10.1038/sc.2016.46; published online 12 April 2016

\section{INTRODUCTION}

Individuals with spinal cord injury (SCI) have several disabilities and sequelae such as loss of locomotor function and bladder, bowel, sexual and autonomic dysfunction. Pain and spasticity are other common and disabling consequences. Up to $80 \%$ of individuals with SCI complain of chronic pain, and they often experience several types of pain. ${ }^{1-3}$ Musculoskeletal pain is the most common pain type seen in about $80 \%$, neuropathic pain is reported by $50-60 \%$ and visceral pain, which becomes increasingly prevalent over time, is present in about $30 \%$ with long-term SCI. ${ }^{1,2,4,5}$ Within these broader categories of pain, different subtypes exist. Neuropathic pain felt at and below the level of injury differs in presentation and probably also mechanisms, ${ }^{1,6,7}$ and even within these subgroups, different phenotypes exist with specific combinations of pain descriptors and sensory abnormalities, which may represent different underlying mechanisms. ${ }^{8,9}$ Chronic pain is associated with poorer psychological functioning and lower quality of life, ${ }^{8,10-14}$ but few studies have looked into the role of specific pain types on quality of life. ${ }^{15,16}$ Spasticity is another common complication present in about $70 \%$ of all SCI after the first year. ${ }^{17}$ Spasticity is a broad term that includes velocity-dependent increase in muscle tone, enhanced tendon reflexes, muscle spasms and clonus. ${ }^{18,19}$ Although mild spasticity may be beneficial, severe spasticity may cause functional impairment, ${ }^{20}$ and spasticity is also suggested to decrease quality of life. $^{21-25}$

Pain and spasticity overlap in individuals with SCI. Spasms may cause musculoskeletal pain, and both below-level central pain and spasticity developed over time can be evoked by non-painful stimuli and show spatial extension, suggesting common underlying mechanisms. In addition, both central neuropathic pain and spasms arise from central neuroplastic changes with neuronal hyperexcitability and loss of inhibition, causing decreased threshold, increased responses and expansion of receptive fields in spinal cord neurons. ${ }^{26}$ Still, very little is known about the correlations between different pain types and spasticity symptoms in individuals with SCI.

Quality of life $\mathrm{e}^{27}$ is generally lower among the SCI than in the general population. ${ }^{11,28-31}$ Many factors, including older and lower age at injury, short time since injury, higher level of lesion, low functional ability, low social support, residence (cohabitation), low income, low mobility, marital status (single), neurogenic bowel and bladder dysfunction, spasticity, pain and pain interference, may be associated with lower quality of life in SCI. $7,11,13,24,30-39$

\footnotetext{
${ }^{1}$ Spinal Cord Injury Centre of Western Denmark, Neurological Department, Regional Hospital of Viborg, Viborg, Denmark; ${ }^{2}$ Clinic for Spinal Cord Injuries, Rigshospitalet, University of Copenhagen, Copenhagen, Denmark; ${ }^{3}$ Department of Clinical Medicine, University of Bergen, Bergen, Norway; ${ }^{4}$ The Autonomic Unit, National Hospital for Neurology and Neurosurgery, University College London, London, UK; ${ }^{5}$ Hammel Neurorehabilitation and Research Center, Hammel, Denmark; ${ }^{6}$ Department of Neurology, Aarhus University Hospital, Aarhus, Denmark and ${ }^{7}$ Danish Pain Research Center, Department of Clinical Medicine, Aarhus University, Aarhus, Denmark Correspondence: Dr SR Andresen, Spinal Cord Injury Centre of Western Denmark, Neurological Department, Regional Hospital of Viborg, Heibergs Allé 4, Viborg DK-8800, Denmark.

E-mail: sven.robert.andresen@midt.rm.dk

Received 21 January 2016; revised 7 March 2016; accepted 7 March 2016; published online 12 April 2016
} 
The purpose of this study was to estimate the prevalence, predictors and impact of self-reported pain and spasticity in a large nationwide study. In addition, we aimed to look at specific subtypes of pain and spasticity and their correlations. The study also evaluated the use of cannabis in the present population. These results are presented elsewhere (Andresen et al. unpublished).

\section{METHODS}

\section{Survey design}

This was a cross-sectional anonymous nationwide postal survey in patients who had been hospitalized or been in contact with one of the two SCI outpatient clinics in Denmark from 1990 to 2012. Participants had to be $\geqslant 18$ years and have suffered a traumatic SCI. The responses were anonymous as the questionnaire also assessed cannabis use among SCI individuals. These results are reported separately (Andresen et al. unpublished).

\section{Questionnaire}

The questionnaire included 35 questions, combining general demographics, SCI characteristics, pain, spasticity, quality of life, sleep disturbance and information on cannabis use, effect and adverse events (Andresen et al. unpublished). As the results on cannabis use are reported elsewhere (Andresen et al. unpublished), this report focuses on pain and spasticity and the impact on quality of life.

\section{Pain}

Participants were asked about chronic pain, defined as continuous or daily recurring pain that had been present for $>3$ months. Participants with chronic pain rated average pain intensity and how much the pain interfered with their day-to-day activities in the last week on a numeric rating scale (NRS, 0-10), where 0 is no pain/no interference and 10 is pain as bad as you can imagine/ extreme interference, using parts of the International Spinal Cord Injury Pain Basic Data Set. ${ }^{40}$ They also filled in the seven-item Douleur Neuropathique 4 questions (DN4 2005, Bouhassira D. All rights reserved). ${ }^{41,42}$ The selection of at least three of the seven pain descriptors (burning, painful cold, electric shocks, tingling, pins and needles, numbness and itching) is suggestive of neuropathic pain with a sensitivity of $81.6 \%$ and a specificity of $85.7 \%$ in the original study ${ }^{41}$ and of $93 \%$ and $75 \%$ in SCI individuals. ${ }^{42}$ Pain treatment was established with a list of multiple treatment options and the possibility to add other treatments.

\section{Spasticity}

Participants were asked whether they had spasticity (muscle stiffness or spasms). If they had spasticity, they rated how much the spasticity interfered with their day-to-day activities in the last week on an NRS (0-10). They also rated the intensity of average muscle stiffness intensity in the last week, and spasm frequency was assessed using the Penn Spasm Frequency Scale. ${ }^{43,44}$ Participants were given a treatment list for spasticity.

\section{Quality of life}

To estimate participants' quality of life, we used the International Spinal Cord Injury Quality of Life Basic Data Set, ${ }^{45}$ which asks about satisfaction with life as a whole, with physical health and with psychological health, emotions and mood. Participants were asked to rate these three factors for the past week on an NRS (0-10), $0=$ completely dissatisfied to $10=$ completely satisfied. Sleep disturbance during the last week was reported using an NRS (0-10).

\section{Statistical analysis}

Data were checked for normality by using histograms and QQ-plots and then described as mean (s.d.) or median (range) or frequency and percentages. Categorical or numerical data were analyzed by using the Chi-square test or Fisher's exact test and an unpaired $t$-test or the Mann-Whitney $U$-test, respectively. For comparisons between three groups (participants with no chronic pain, participants with chronic pain with descriptors not suggestive of neuropathic pain and participants with chronic pain and descriptors suggestive of neuropathic pain), we first used Bartlett's test to show that there was no significant $(P>0.05)$ difference in variance between the groups; then, we used one-way ANOVA with Bonferroni multiple comparison tests to analyze the differences in quality-of-life outcome scores between the three groups. The factors that showed association with quality-of-life questions in previous studies within this population were included in a multivariate regression model. Data missing in different variables were $<2.4 \%$. Statistical analysis was performed with STATA release 12 (StataCorp, College Station, TX, USA). $P$-values $<0.05$ were considered statistically significant.

\section{Statement of ethics}

Approvals to conduct the study were given by the Danish Health and Medicines Authority, Copenhagen, Denmark (no. 3-3013-621/1) and the Danish Data Protection Agency, Copenhagen, Denmark (no. 1-16-02-210-14). All applicable institutional and governmental regulations concerning the ethical use of human volunteers were followed during the course of this research.

\section{RESULTS}

The questionnaire was sent out to 1101 individuals of which 544 responded (response rate 49.4\%), and 537 responses were included in the analysis ( 7 were excluded because questionnaires were incomplete on main outcomes, further details in Andresen et al. unpublished).

Table 1 Demographics and clinical characteristics of the spinal cord injury $(\mathrm{SCl})$ individuals included

\begin{tabular}{lc}
\hline & Total $(\mathrm{n}=537)$ \\
\hline Age, years, mean (s.d.), $n=537$ & $54.6(14.6)$ \\
Gender, male, $n$ (\%), $n=537$ & $413(77)$ \\
Time since SCl, years, mean (s.d.), $n=532$ & $18.2(12.8$ \\
& \\
SCl impact on everyday life, $n$ (\%), $n=534$ & \\
Not at all & $16(3)$ \\
Some & $106(20)$ \\
$\quad$ Moderate & $186(35)$ \\
Much & $226(42)$
\end{tabular}

Quality of life, NRS 0-10, mean (s.d.)

Satisfaction with life and life situation, $n=532$

Satisfaction with physical health, $n=532$

$5.5(2.6)$

Satisfaction with mental health, feeling, mood, $n=531$

Sleep disturbance, NRS 0-10, mean (s.d.), $n=534$

Pain, $n(\%), n=536$

Participants with pain

Pain intensity, NRS 0-10, mean (s.d.), $n=378$

$5.6(2.3)$

Pain interference, NRS 0-10, mean (s.d.), $n=379$

$5.0(2.8)$

Drug treatment for pain, $n(\%), n=389$

259 (67)

Spasticity, $n(\%), n=536$

$378(71)$

Spasm frequency, $n$ (\%), $n=533$

No spasms

$172(32)$

Mild spasms induced by stimulation

189 (35)

Infrequent full spasms occurring $<1$ per hour 111 (21)

Spasms occurring $>1$ per hour

$42(8)$

Spasms occurring $>10$ times per hour

\section{Participants with spasticity}

Muscle stiffness intensity, NRS 0-10, mean (s.d.), $n=366$

Spasticity interference, NRS 0-10, mean (s.d.), $n=367$

Penn Spasms Frequency Scale score, 0-4, mean (s.d.),

$n=375$

Drug treatment for spasticity, $n(\%), n=377$

$172(46)$

Abbreviation: NRS, numeric rating scale. 


\section{Demographics and SCI characteristics}

The average age was 54.6 (s.d. 14.6) years and $77 \%$ were men (Table 1). Sixty-five percent reported that they were unemployed, $19 \%$ had part-time work and 16\% full-time work. Fourteen percent (74 of 530) of the participants reported that they drank more alcohol per week than recommended by the Danish Health and Medicines Authority (14 units for men and 7 units for women). Twenty-six percent of the participants smoked cigarettes daily or sometimes. Forty-nine percent were paraplegics, $64 \%$ had an incomplete SCI and mean time since injury was estimated to be 18.2 (s.d. 12.8) years. The leading reasons for their traumatic SCI were transportation (41\%) and fall (30\%). For detailed description, please see Andresen et al. unpublished.

\section{Pain}

Chronic pain was reported by $73 \%$ (390/536). The average pain intensity was 5.6 (s.d. 2.3): $21 \%$ reported mild pain (NRS 1-4), $22 \%$ moderate pain (NRS 5-6), and 28\% severe pain (NRS 7-10). Pain interference in day-to-day activities was 5.0 (s.d. 2.8). Pain

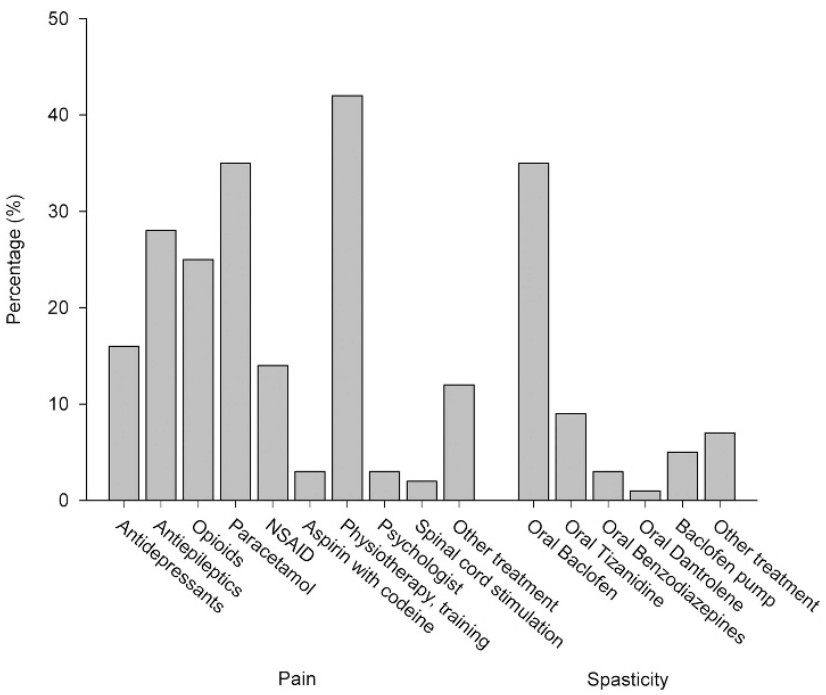

Figure 1 Treatments reported for pain $(n=390)$ and spasticity $(n=378)$. Other pain treatment included methadone, acupuncture, transcutaneous electrical nerve stimulation, massage, cranio-sacral therapy, cannabis oil, mindfulness/meditation and hot water basin and other treatment for spasticity included physical therapy, botulinum toxin, cannabis and acupuncture. treatment was reported by $67 \%$ (259 of 390 ), and the most common type was physiotherapy/training (Figure 1).

Two hundred and thirty-four participants had a DN4 score of $\geqslant 3$ corresponding to $60 \%$ of those with pain and $43.6 \%$ of the total sample. The average DN4 score among those with pain was 3.1 (s.d. 1.7). Participants with a DN4 score $\geqslant 3$ had a significantly higher average pain intensity and pain interference (6.0 (s.d. 2.1) and 5.5 (s.d. 2.7), respectively) than those with a DN4 score $<3$ (5.0 (s.d. 2.5) and 4.3 (s.d. 2.9), respectively) $(P<0.001)$. The most common descriptors were pins and needles (75\%), burning (60\%) and tingling $(59 \%)$ (Table 2). Significantly more tetraplegics than paraplegics reported painful cold $(P=0.02)$, and more participants with an incomplete SCI had painful cold $(P=0.01)$, numbness $(P=0.003)$ and itching $(P=0.03)$ than those with a complete SCI (Table 2$)$.

\section{Spasticity}

Spasticity was reported by 71\% (378 of 536) participants, of these 356 (94\%) reported muscle stiffness and 361 (95.5\%) muscle spasms. Among those with spasticity, the average muscle stiffness intensity was 3.9 (s.d. 2.4) and the average interference was 2.9 (s.d. 2.7). Thirty-three percent had mild (NRS 1-3), 23\% moderate (NRS 4-6) and $12 \%$ severe (NRS 7-10) muscle stiffness. Among those with spasms, the average spasm score was 1.63 (s.d. 0.9); 83\% (300/361) had mild or infrequent spasms and 17\% (61/361) had more than one spasms per hour (Table 1). One hundred and seventy-two (46\%)

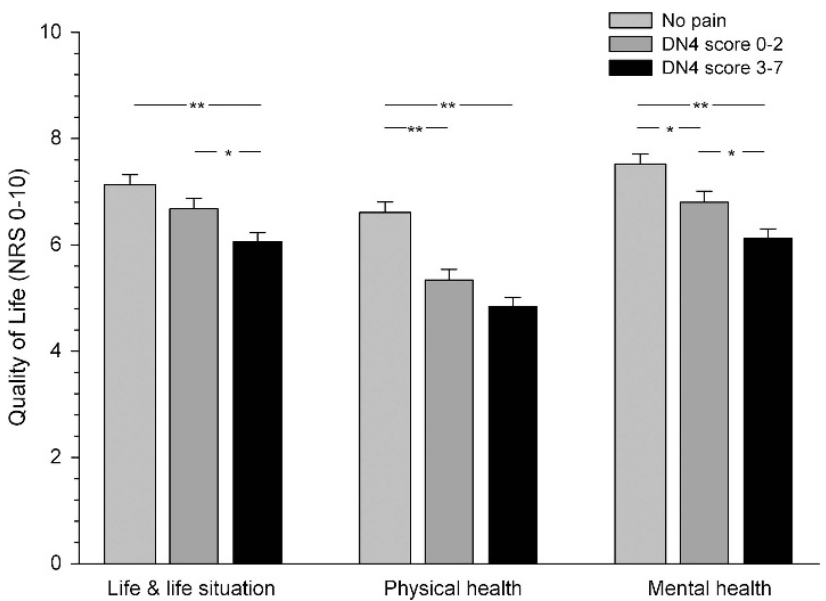

Figure 2 Quality-of-life scores for participants without pain $(n=146)$, pain and a DN4 score $<3(n=156)$ and pain and a DN4 score $\geqslant 3(n=234)$. ${ }^{*} P<0.05 ;{ }^{* *} P<0.001$. Error bars are s.e.m.

Table 2 Pain descriptors in spinal cord-injured individuals with different lesion levels and injury severity

\begin{tabular}{|c|c|c|c|c|c|c|c|}
\hline & Total $(\mathrm{n}=390)$ & Paraplegic & Tetraplegic & $\mathrm{P}$-value & Incomplete & Complete & P-value \\
\hline \multicolumn{8}{|c|}{ Pain descriptors, n (\%) } \\
\hline Burning & $234(60)$ & $117(44)$ & $110(45)$ & 0.89 & $151(44)$ & $75(45)$ & 0.74 \\
\hline Painful cold & $99(25)$ & $40(15)$ & $57(23)$ & 0.02 & $76(22)$ & $21(13)$ & 0.01 \\
\hline Electric shocks & $146(37)$ & 77 (29) & $63(26)$ & 0.38 & $100(29)$ & $41(25)$ & 0.32 \\
\hline \multicolumn{8}{|c|}{ Associated symptoms, $n(\%)$} \\
\hline Tingling & $230(59)$ & $108(41)$ & $111(45)$ & 0.32 & $147(43)$ & $70(42)$ & 0.95 \\
\hline Pins and needles & $291(75)$ & $143(54)$ & $134(55)$ & 0.90 & $185(54)$ & $94(57)$ & 0.5 \\
\hline Numbness & $144(37)$ & $66(25)$ & $72(30)$ & 0.27 & $108(31)$ & 31 (19) & 0.003 \\
\hline Itching & $67(17)$ & $32(12)$ & $31(13)$ & 0.86 & $51(15)$ & $13(8)$ & 0.03 \\
\hline
\end{tabular}

Bold values represent $P$-values less than 0.05 . 


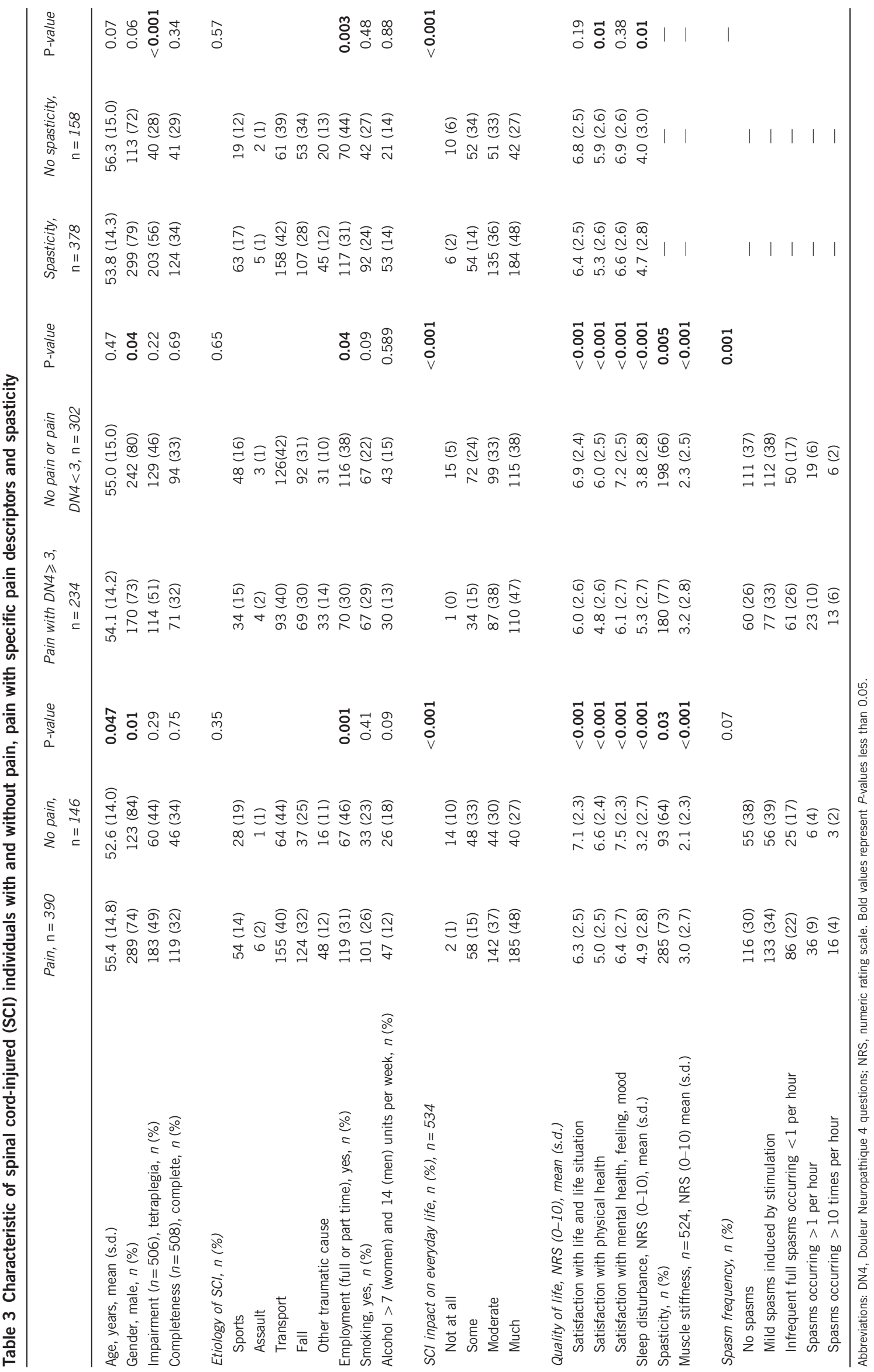


Table 4 Demographic and clinical characteristics assessed for association with quality of life in a multivariate a regression model

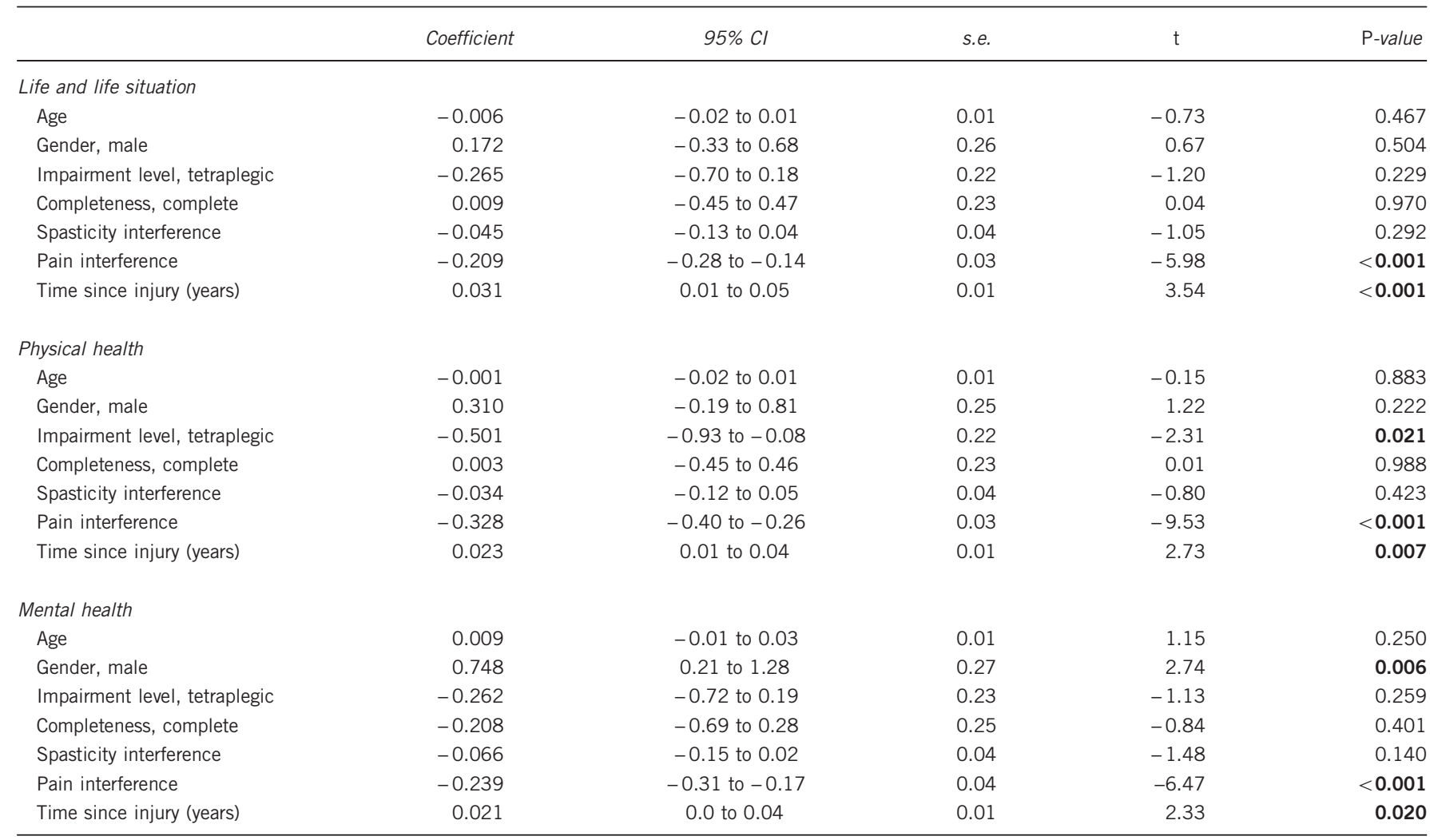

Abbreviation: $\mathrm{Cl}$, confidence interval. Bold values represent $P$-values less than 0.05 .

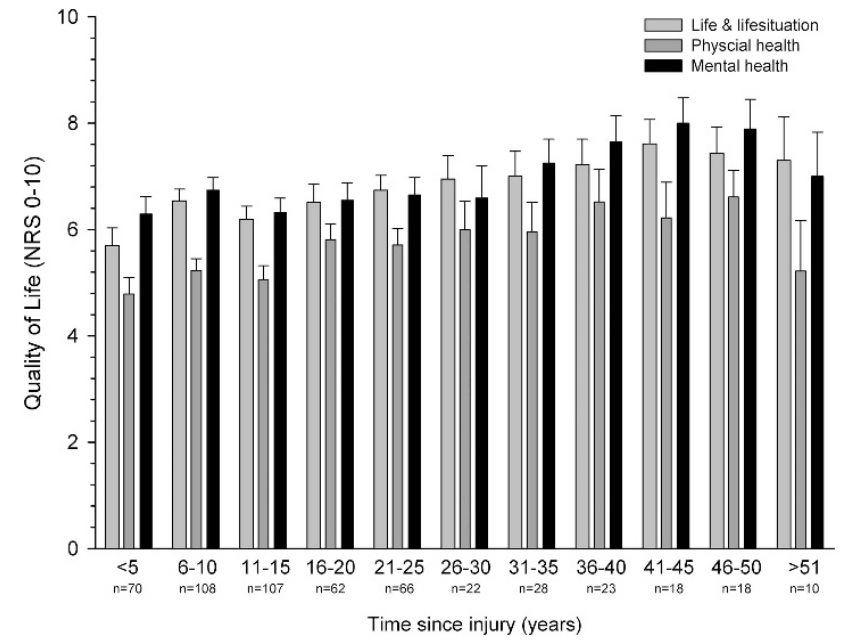

Figure 3 Mean score on all three quality-of-life items compared to time since injury (years). Error bars are s.e.m.

reported treatment for spasticity. Baclofen was the most frequently used medication for spasticity used by $40 \%$ (35\% oral and 5\% pump) of those with spasticity (Figure 1).

\section{Quality of life}

Seventy-seven percent $(412 / 534)$ stated that their traumatic SCI had at least moderate influence on their daily life (Table 1 ). The mean quality of life scores was between 5.5 and 6.7, with the lowest score for physical health (Table 1). Participants with pain and a DN4 score $\geqslant 3$ had significantly lower quality-of-life scores than those without pain $(P<0.001)$ and lower scores than participants with pain and a DN4 score $<3$ for physical and mental health $(P<0.05)$ (Figure 2).

Variables associated with pain and spasticity

We compared demographics, SCI-related factors and quality of life among participants with and without pain, with and without pain with a DN4 score $\geqslant 3$ and with and without spasticity in univariate analyses (Table 3). Participants with pain were significantly older, more often female, less often employed and had a significantly higher impact of SCI on everyday life, sleep disturbance and muscle stiffness score and lower quality of life scores than those without pain (Table 3). Participants with pain and a DN4 score $\geqslant 3$ also had a higher spasm frequency score than those without. Participants with spasticity were more often tetraplegic and unemployed and had a higher impact of SCI on everyday life and sleep disturbance and lower satisfaction with physical health (Table 3).

Variables associated with quality of life

Variables suggested to be associated with quality of life in SCI in previous studies $7,11,13,24,30-39$ were included in a multivariate regression model (Table 4). Female gender was associated with lower mental health scores (Table 4). High pain interference and shorter time since injury were associated with lower quality-of-life scores for all three parameters (Table 4). Tetraplegia was associated with lower physical health scores (Table 4). In total, quality-of-life items as life and life situation could be explained by $12.9 \%$, physical health by $22.6 \%$ and mental health by $14.8 \%$ with the variables included. The quality-of-life scores increased with increasing time since injury up to $40-45$ years 
after injury, after which they decreased again (Figure 3). There was a significant trend over time since injury for the three different parameters of quality of life $(P \leqslant 0.001$; test for trend across ordered groups).

\section{DISCUSSION}

In this large nationwide questionnaire study of individuals who had sustained a traumatic SCI at least 3 years prior to the study, we found a prevalence of chronic pain of $73 \%$, of chronic pain with typical neuropathic pain characteristics of $44 \%$ and of spasticity of $71 \%$, supporting that these symptoms are frequent in this population. ${ }^{1,5,7,12,46-51}$ Almost $50 \%$ of all participants had at least moderate pain and $28 \%$ had severe pain. Of those with chronic pain, $67 \%$ received treatment, most often physiotherapy and training followed by antiepileptics, paracetamol and opioids, whereas $46 \%$ of those with spasticity received treatment for this, most often baclofen. Pain was on average rated as more intense and had a higher interference on daily life than spasticity. In univariate analysis, individuals with spasticity had lower satisfaction with physical health than those without, whereas pain was associated with lower satisfaction in all three domains of life situation, physical health and mental health. Similarly, interference of pain but not spasticity was associated with lower quality of life. Both pain and spasticity were associated with unemployment and sleep disturbance.

Participants with pain and a DN4 score $\geqslant 3$, which suggests the presence of neuropathic pain, reported higher pain intensity and pain interference and had a lower satisfaction with their life situation and mental health than those with pain and a DN4 score $<3$. Pins and needles (75\%), burning (60\%) and tingling (59\%) were the most common pain descriptors. Painful cold, numbness and itching were more often reported in those with an incomplete than a complete SCI, suggesting that, at least in the Danish version, numbness is not a measure of loss of sensation but rather reflects abnormal evoked sensations. Consistent with most previous studies, ${ }^{5}$ we found no clear relation between pain and injury-specific characteristics, whereas spasticity expectedly was more common in individuals with tetraplegia compared with paraplegia, which includes cauda equina. Individuals with pain were slightly older than those without pain, consistent with other studies, ${ }^{12,52,53}$ and were more often female. Individuals with pain more often had spasticity and higher muscle stiffness than those without pain and those with pain and a DN4 score $\geqslant 3$ also had more spasms. Although treatment may impact the presence and severity of pain and spasticity, this may reflect that spasticity can cause musculoskeletal pain and also supports previous suggestions that neuropathic pain and spasms share underlying pathophysiological mechanisms. ${ }^{54}$ We saw an increase in quality of life with increased time since injury up to 45 years after injury. A similar increase in quality of life has also been described in prospective studies. ${ }^{7,13}$ A high pain interference was associated with a low quality of life for all three domains. We have previously shown that an increase in quality of life over time correlated with an increase in change in pain interference, ${ }^{7}$ suggesting that efforts to minimize pain's impact are important. Being tetraplegic was only associated with lower satisfaction with physical health. Several other consequences of SCI that have been shown to impact quality of life, such as hand function, bowel, bladder and sexual dysfunction and cardiovascular autonomic dysfunction, were not addressed in our study. ${ }^{11,13,29,34,35,37}$

\section{Limitations}

We had a relatively low response rate of $49 \%$, which may be explained by the inclusion of questions related to cannabis use, which is illegal in
Denmark. In addition, as the questionnaire for this reason was anonymous, we could not send out reminders or do an analysis of dropouts. However, our population was representative of the Danish SCI population with respect to gender, age and SCI characteristics (Andresen et al. unpublished). This limitation is most important for the frequency; the data on the correlation between symptoms and 'consequence' are not influenced as much. Another limitation is that the results rely on self-report. Although pain descriptors may be suggestive of neuropathic pain, we cannot determine the type of pain with certainty without a detailed pain history and clinical examination.

\section{CONCLUSION}

We confirm that pain and spasticity are common and disabling consequences of a traumatic SCI. As a new finding, we show that pain seemed to have more impact on quality of life than spasticity and that pain with descriptors suggestive of neuropathic pain was rated as more severe and with higher interference and associated with lower qualityof-life scores than pain without such descriptors. There was no relation between pain and injury-specific characteristics, but spasticity was more common in individuals with tetraplegia, and there was an association between the presence of pain and spasticity. We found that high pain interference, shorter time since injury, female gender and tetraplegia were associated with lower quality-of-life scores. The study emphasizes the need for attention to pain and spasticity in the SCI population and that further research on improving the treatment of pain and spasticity is important.

\section{DATA ARCHIVING}

There were no data to deposit.

\section{CONFLICT OF INTEREST}

NBF reports honoraria from Pfizer and Grünenthal and grants from IMI Europain (EU/EFPIA) outside the submitted work. FWB has received investigator fees from Pfizer and Grunenthal. The remaining authors declare no conflict of interest.

\section{ACKNOWLEDGEMENTS}

Region Midtjyllands Sundhedsvidenskabelige Forskningsfond and The Danish Society of Polio and Accident Victims (PTU) supported the study. All authors had full access to all data, and the corresponding author had the final responsibility for the decision to submit for publication.

1 Siddall PJ, McClelland JM, Rutkowski SB, Cousins MJ. A longitudinal study of the prevalence and characteristics of pain in the first 5 years following spinal cord injury. Pain 2003; 103: 249-257.

2 Finnerup NB, Norrbrink C, Trok K, Piehl F, Johannesen IL, Sørensen JC et al. Phenotypes and predictors of pain following traumatic spinal cord injury: a prospective study. J Pain 2014; 15: 40-48.

3 Siddall PJ, Finnerup NB. Chapter 46 Pain following spinal cord injury. Handb Clin Neurol 2006; 81: 689-703.

4 Finnerup NB, Faaborg P, Krogh K, Jensen TS. Abdominal pain in long-term spinal cord injury. Spinal Cord 2008; 46: 198-203.

5 Dijkers M, Bryce T, Zanca J. Prevalence of chronic pain after traumatic spinal cord injury: a systematic review. J Rehabil Res Dev 2009; 46: 13-29.

6 Bryce TN, Biering-Sørensen F, Finnerup NB, Cardenas DD, Defrin R, Lundeberg T et al. International Spinal Cord Injury Pain Classification: part I. Background and description. Spinal Cord 2012; 50: 413-417.

7 Finnerup NB, Jensen MP, Norrbrink C, Trok K, Johannesen IL, Jensen TS et al. A prospective study of pain and psychological functioning following traumatic spinal cord injury. Spinal Cord (epub ahead of print 1 March 2016; doi:10.1038/ sc.2015.236).

8 Finnerup NB. Pain in patients with spinal cord injury. Pain 2013; 154: S71-S76.

9 von Hehn CA, Baron R, Woolf CJ. Deconstructing the neuropathic pain phenotype to reveal neural mechanisms. Neuron 2012; 73: 638-652. 
10 Putzke JD, Richards JS, Hicken BL, DeVivo MJ. Interference due to pain following spinal cord injury: important predictors and impact on quality of life. Pain 2002; 100 231-242.

11 Westgren N, Levi R. Quality of life and traumatic spinal cord injury. Arch Phys Med Rehabil 1998; 79: 1433-1439.

12 Rintala DH, Loubser PG, Castro J, Hart KA, Fuhrer MJ. Chronic pain in a communitybased sample of men with spinal cord injury: prevalence, severity, and relationship with impairment, disability, handicap, and subjective well-being. Arch Phys Med Rehabil 1998; 79: 604-614.

13 van Leeuwen CMC, Post MWM, van Asbeck FWA, Bongers-Janssen $\mathrm{HMH}$ van der Woude LHV, de Groot S et al. Life satisfaction in people with spinal cord injury during the first five years after discharge from inpatient rehabilitation. Disabil Rehabil 2012; 34: 76-83.

14 Widerström-Noga E, Felipe-Cuervo E, Yezierski R. Relationships among clinical characteristics of chronic pain after spinal cord injury. Arch Phys Med Rehabil 2001; 82: 1191-1197.

15 Nagoshi N, Kaneko S, Fujiyoshi K, Takemitsu M, Yagi M, lizuka S et al. Characteristics of neuropathic pain and its relationship with quality of life in 72 patients with spinal cord injury. Spinal Cord 2016; 54: 656-661.

16 Gormsen L, Rosenberg R, Bach FW, Jensen TS. Depression, anxiety, health-related quality of life and pain in patients with chronic fibromyalgia and neuropathic pain. Eur J Pain 2010; 14: 127.e1-127.e8.

17 Biering-Sørensen F, Nielsen JB, Klinge K. Spasticity-assessment: a review. Spinal Cord 2006; 44: 708-722.

18 Sheean G. The pathophysiology of spasticity. Eur J Neurol 2002; 9: 3-9 (dicussion 53-61).

19 Pandyan A, Gregoric M, Barnes M, Wood D, Wijck F, Van, Burridge J et al. Spasticity: clinical perceptions, neurological realities and meaningful measurement. Disabil Rehabil 2005; 27: 2-6.

20 Sezer N. Chronic complications of spinal cord injury. World J Orthop 2015; 6: 24-33.

21 Rekand T, Hagen EM, Grønning M. Spasticity following spinal cord injury. Tidsskr Nor Laegeforen 2012; 132: 970-973.

22 Adams MM, Hicks AL. Spasticity after spinal cord injury. Spinal Cord 2005; 43 : 577-586.

23 Gianino JM, York MM, Paice JA, Shott S. Qol spasticity after intrathecal baclofen. J Neurosci Nurs 1998; 30: 47-54.

24 Westerkam D, Saunders LL, Krause JS. Association of spasticity and life satisfaction after spinal cord injury. Spinal Cord 2011; 49: 990-994.

25 Krause JS, Zhai Y, Saunders LL, Carter RE. Risk of mortality after spinal cord injury: an 8-year prospective study. Arch Phys Med Rehabil 2009; 90: 1708-1715.

26 Brown A, Weaver LC. The dark side of neuroplasticity. Exp Neurol 2012; 235: 133-141.

27 Post M. Definitions of quality of life: what has happened and how to move on. Top Spinal Cord Inj Rehabil 2014; 20: 167-180.

28 Boakye M, Leigh BC, Skelly AC. Quality of life in persons with spinal cord injury: comparisons with other populations. J Neurosurg Spine 2012; 17: 29-37.

29 Kreuter M, Siösteen A, Erkholm B, Byström U, Brown DJ. Health and quality of life of persons with spinal cord lesion in Australia and Sweden. Spinal Cord 2005; 43: 123-129.

30 Lidal IB, Veenstra M, Hjeltnes N, Biering-Sørensen F. Health-related quality of life in persons with long-standing spinal cord injury. Spinal Cord 2008; 46: 710-715.

31 Middleton J, Tran Y, Craig A. Relationship between quality of life and self-efficacy in persons with spinal cord injuries. Arch Phys Med Rehabil 2007; 88 1643-1648.

32 Mortenson WB, Noreau L, Miller WC. The relationship between and predictors of quality of life after spinal cord injury at 3 and 15 months after discharge. Spinal Cord 2010, 48: 73-79.
33 Dijkers MPJM. Quality of life of individuals with spinal cord injury: a review of conceptualization, measurement, and research findings. J Rehabil Res Dev 2005; 42 (Supp 1): 87-110.

34 Hammell KW. Exploring quality of life following high spinal cord injury: a review and critique. Spinal Cord 2004; 42: 491-502.

35 Erosa NA, Berry JW, Elliott TR, Underhill AT, Fine PR. Predicting quality of life 5 years after medical discharge for traumatic spinal cord injury. Br J Health Psychol 2014; 19 688-700.

36 Widerstrom-Noga EG, Felipe-Cuervo E, Yezierski RP. Chronic pain after spinal injury: interference with sleep and daily activities. Arch Phys Med Rehabil 2001; 82 1571-1577

37 Adriaansen JJE, van Asbeck FWA, Tepper M, Faber WX, Visser-Meily JMA, de Kort LMO et al. Bladder-emptying methods, neurogenic lower urinary tract dysfunction and impact on quality of life in people with long-term spinal cord injury. J Spinal Cord Med 2015; 0: $1-11$.

38 Dijkers MP. Correlates of life satisfaction among persons with spinal cord injury. Arch Phys Med Rehabil 1999; 80: 867-876.

39 Trgovcevic S, Milicevic M, Nedovic G, Jovanic G. Health condition and quality of life in persons with spinal cord injury. Iran J Public Health 2014; 43: 1229-1238.

40 Widerström-Noga E, Biering-Sørensen F, Bryce TN, Cardenas DD, Finnerup NB, Jensen MP et al. The International Spinal Cord Injury Pain Basic Data Set (version 2.0). Spinal Cord 2014; 52: 282-286.

41 Bouhassira D, Attal N, Alchaar H, Boureau F, Brochet B, Bruxelle J et al. Comparison of pain syndromes associated with nervous or somatic lesions and development of a new neuropathic pain diagnostic questionnaire (DN4). Pain 2005; 114: 29-36.

42 Hallström H, Norrbrink C. Screening tools for neuropathic pain: can they be of use in individuals with spinal cord injury? Pain 2011; 152: 772-779.

43 Penn RD, Savoy SM, Corcos D, Latash M, Gottlieb G, Parke B et al. Intrathecal baclofen for severe spinal spasticity. N Engl J Med 1989; 320: 1517-1521.

44 Priebe MM, Sherwood AM, Thornby JI, Kharas NF, Markowski J. Clinical assessment of spasticity in spinal cord injury: a multidimensional problem. Arch Phys Med Rehabil 1996; 77: 713-716.

45 Charlifue S, Post MW, Biering-Sørensen F, Catz A, Dijkers M, Geyh S et al. International spinal cord injury quality of life basic data set. Spinal Cord 2012; 50: 672-675.

46 Ravenscroft A, Ahmed YS, Burnside IG. Chronic pain after SCI. A patient survey. Spinal cord 2000; 38: 611-614.

47 Finnerup NB, Johannesen IL, Sindrup SH, Bach FW, Jensen TS. Pain and dysesthesia in patients with spinal cord injury: a postal survey. Spinal Cord 2001; 39: 256-262.

48 Norrbrink Budh C, Lund I, Ertzgaard P, Holtz A, Hultling C, Levi R et al. Pain in a Swedish spinal cord injury population. Clin Rehabil 2003; 17: 685-690.

49 Turner JA, Cardenas DD, Warms CA, McClellan CB. Chronic pain associated with spinal cord injuries: a community survey. Arch Phys Med Rehabil 2001; 82: 501-508.

50 Störmer S, Gerner HJ, Grüninger W, Metzmacher K, Föllinger S, Wienke C et al. Chronic pain/dysaesthesiae in spinal cord injury patients: results of a multicentre study. Spinal Cord 1997; 35: 446-455.

51 Werhagen L, Budh CN, Hultling C, Molander C. Neuropathic pain after traumatic spinal cord injury - relations to gender, spinal level, completeness, and age at the time of injury. Spinal Cord 2004; 42: 665-673.

52 Fenollosa P, Pallares J, Cervera J, Pelegrin F, Inigo V, Giner M et al. Chronic pain in the spinal cord injured: statistical approach and pharmacological treatment. Paraplegia 1993; 31: 722-729.

53 Richards JS, Meredith RL, Nepomuceno C, Fine PR, Bennett G. Psycho-social aspects of chronic pain in spinal cord injury. Pain 1980; 8: 355-366.

54 Vierck CJ, Cannon RL, Stevens KA, Acosta-Rua AJ, Wirth ED. Mechanisms of increased pain sensitivity within dermatomes remote from an injured segment of the spinal cord. In: Yezierski RP, Burridge KJ (eds). Spinal Cord Injury Pain: Assessment, Mechanisms, Management. Progress in Pain Research and Management. IASP Press: Seattle, WA, USA, 2002, pp 155-173. 